\title{
Thymosin $\alpha 1$ treatment reduces hepatic inflammation and inhibits hepatocyte apoptosis in rats with acute liver failure
}

\author{
XUELIANG YANG ${ }^{1}$, YUNRU CHEN ${ }^{1}$, JIAN ZHANG ${ }^{2}$, TIANTIAN TANG ${ }^{3}$, YING KONG ${ }^{1}$, \\ FENG YE $^{1}$, XI ZHANG ${ }^{1}$, XIAOJING LIU ${ }^{1}$ and SHUMEI LIN ${ }^{1}$ \\ ${ }^{1}$ Department of Infectious Diseases, The First Affiliated Hospital of Xi'an Jiaotong University, Xi'an, Shaanxi 710061; \\ ${ }^{2}$ The Second Department of Gastroenterology, Shaanxi Provincial People's Hospital, Xi'an, Shaanxi 710068; \\ ${ }^{3}$ Department of Infectious Diseases, Xi'an Children's Hospital, Xi'an, Shaanxi 710003, P.R. China
}

Received December 19, 2016; Accepted November 20, 2017

DOI: $10.3892 / \mathrm{etm} .2018 .5843$

\begin{abstract}
The present study aimed to evaluate whether thymosin $\alpha 1$ (T $\alpha 1)$ increases survival rates through the improvement of immunofunction and inhibition of hepatocyte apoptosis in rats with acute liver failure (ALF). A total of 25 rats were randomly divided into the control group (CG), the model group (MG) and the treatment group (TG). The CG received an intraperitoneal injection of saline $(2 \mathrm{ml})$. The ALF rat model was established by the intraperitoneal injection of D-galactosamine $(700 \mathrm{mg} / \mathrm{kg}$ ) and lipopolysaccharide $(10 \mu \mathrm{g} / \mathrm{kg})$. The TG received an intraperitoneal injection of Tal $(0.03 \mathrm{mg} / \mathrm{kg}) 1 \mathrm{~h}$ prior to and $30 \mathrm{~min}$ after modeling. The survival rates of the rats were recorded. An additional 63 rats were randomly divided into a $\mathrm{CG}(\mathrm{n}=3), \mathrm{MG}(\mathrm{n}=30)$ and TG $(n=30)$. Three rats were sacrificed at 3, 6, 9 and $12 \mathrm{~h}$ after establishment of the rat model to detect plasma alanine transaminase (ALT), aspartate transaminase (AST), total bilirubin (TBIL), tumor necrosis factor (TNF)- $\alpha$ and interleukin-10 (IL-10). Liver samples were stained with hematoxylin and eosin and TUNEL, and reverse transcription-quantitative polymerase chain reaction and western blot analysis were performed to detect B-cell lymphoma 2 (Bcl-2) and $\mathrm{Bcl}-2$-associated $\mathrm{X}$ protein $(\mathrm{Bax})$ in liver tissue. The results indicated that the survival rate of the TG was significantly higher compared with that of the $\mathrm{MG}$ at $24 \mathrm{~h}(\mathrm{P}<0.05)$. Plasma ALT, AST and TBIL in the MG and TG increased over time (3-12 h), with ALT, AST and TBIL observed to be significantly lower in the TG compared with the MG at each time-point $(\mathrm{P}<0.05)$. Hepatocellular necrosis, hemorrhage and inflammatory cell infiltration of ALF were aggravated over
\end{abstract}

Correspondence to: Professor Shumei Lin, Department of Infectious Diseases, The First Affiliated Hospital of Xi'an Jiaotong University, 277 West Yanta Road, Xi'an, Shaanxi 710061, P.R. China E-mail: linshumei123@126.com

Key words: thymosin $\alpha 1$, acute liver failure, interleukin-10, tumor necrosis factor- $\alpha$, B-cell lymphoma 2, B-cell lymphoma 2-associated $\mathrm{X}$ protein time (3-12 h) in the MG and TG. Notably, in the Ta1-treated rats, the hepatocytes appeared healthier with fewer apoptotic cells compared with those from the MG at the same timepoints. Hepatocyte apoptotic index increased in the TG and MG, but was significantly lower in the TG compared with the MG at each time-point $(\mathrm{P}<0.05)$ in TUNEL assays. Plasma TNF- $\alpha$ and IL-10 in the MG and TG increased over time (3-12 h), with TNF- $\alpha$ observed to be significantly lower in the TG compared with the MG at each time-point $(\mathrm{P}<0.05)$, however, IL-10 was observed to be significantly higher in the TG compared with the MG at each time-point $(\mathrm{P}<0.05)$. Bax mRNA expression was significantly lower in the TG compared with the MG at each time-point $(\mathrm{P}<0.05)$, whereas $\mathrm{Bcl}-2$ was significantly higher $(\mathrm{P}<0.05)$. In conclusion, $\mathrm{T} \alpha 1$ improved survival rates in an ALF rat model by downregulating TNF- $\alpha$ and upregulating IL-10, leading to the attenuation of hepatic inflammation and hepatocyte apoptosis.

\section{Introduction}

Acute liver failure (ALF) is a heterogeneous syndrome, which results in rapid deterioration of liver function with coagulopathy and encephalopathy, and induces systemic inflammation and multiple organ failure $(1,2)$. The primary causes of ALF (including, hepatitis B virus infection, acute viral hepatitis, alcohol and hepatotoxic drugs) are variable and the mortality rate is high, $\sim 60-80 \%$ of individuals suffer mortality after contracting ALF $(3,4)$. Liver transplantation is the only effective therapy, but financial burden, graft shortage and possible life-threatening complications for donors present important limitations (5). Therefore, ALF continues to lack a widely available and effective therapy.

Immune system imbalance serves a critical function in the course of ALF $(6,7)$. In particular, pro-inflammatory and anti-inflammatory cytokine imbalance in the liver and circulation triggers exaggerated immune response and induces adverse outcomes in ALF (3). During the progression of ALF, high levels of pro-inflammatory cytokines trigger the synthesis and release of anti-inflammatory cytokines. These anti-inflammatory cytokines inhibit pathogenic inflammation, but also suppress immune function, resulting in the development of a compensatory anti-inflammatory response (3). The 
relationship between pro-inflammatory and anti-inflammatory cytokine responses is complex (8).

Immune deregulation is now recognized as being critical in ALF pathogenesis, and immune modulation has become a key aspect of ALF treatment $(9,10)$. Thymosin $\alpha 1$ (T $\alpha 1)$, a 28-amino acid peptide, has multiple biological activities. T $\alpha 1$ was originally considered to primarily increase T-lymphocyte function, and has been used in the treatment of chronic cancer, immune deficiencies and hepatitis B virus infection (11-13). However, $\mathrm{T} \alpha 1$ has also been identified to act as an endogenous regulator of innate and adaptive immune systems (14). Ta1 serves a unique function in balancing pro-inflammatory and anti-inflammatory cytokine production through the regulation of distinct Toll-like receptors (TLRs) on different dendritic cell subsets (15). Immune system deregulation serves a critical function in the course of sepsis. T $\alpha 1$ has exhibited beneficial effects in late-stage clinical trials for the treatment of sepsis $(16,17)$. However, to the best of our knowledge, whether T $\alpha 1$ is able to regulate the immune system in ALF has not yet been investigated.

In the present study, a rat model of D-galactosamine hydrochloride (D-GalN)/lipopolysaccharide (LPS)-induced ALF was used in order to evaluate the efficacy of T $\alpha 1$ and its mechanism of action. More precisely, the present study aimed to quantify the T $\alpha 1$-induced pro-inflammatory and anti-inflammatory effects and the expression of B-cell lymphoma 2 (Bcl-2) and Bcl-2-associated X protein (Bax) associated with hepatocyte apoptosis and to evaluate the potential therapeutic interest of T $\alpha 1$ for ALF.

\section{Materials and methods}

Animals and diets. A total of 88 specific-pathogen-free 6-week-old male Sprague-Dawley rats (weighing 180-220 g) were purchased from the Laboratory Animal Center of Xi'an Jiaotong University Health Science Center (Xi'an, China). Rats were housed at a temperature of $23-25^{\circ} \mathrm{C}$ with a 12 -h light/dark cycle and $60-70 \%$ humidity. Standard rodent food and water were supplied ad libitum and rats were housed for 3 days prior to the experiment to enable them to acclimatize to their environment.

Drugs and reagents. T $\alpha 1$ was purchased from SciClone Pharmaceuticals, Inc. (Foster City, CA, USA). LPS and D-GalN were both purchased from Sigma-Aldrich (Merck KGaA, Darmstadt, Germany), and dissolved in aseptic normal saline. Rabbit anti-mouse Bcl-2 (cat. no. ab59348), Bax (cat. no. ab53154) and GAPDH (cat. no. ab8245) were all purchased from Abcam (Cambridge, UK). Horseradish peroxidase (HRP)-labeled goat anti-rabbit antibody (cat. no. TA130015) was purchased from OriGene Technologies, Inc. (Beijing, China). ELISA kits for interleukin-10 (IL-10; cat. no. EA100170) and tumor necrosis factor- $\alpha$ (TNF- $\alpha$; cat. no. EA101768) were purchased from OriGene Technologies, Inc. The In-Situ Apoptosis Detection kit was obtained from Promega Corporation (Madison, WI, USA). Total RNA Extraction kits were purchased from Omega Bio-Tek, Inc. (Norcross, GA, USA). The Sensiscript RT kit was purchased from Qiagen, Inc. (Valencia, CA, USA). SYBR-Green Master mix was obtained from Applied Biosystems (Thermo Fisher Scientific, Inc., Waltham, MA, USA).
Animal grouping and drug administration. A total of 88 rats were randomly divided into two groups. One group of 25 rats was randomly subdivided into a control group (CG; saline, $\mathrm{n}=5$ ), model group (MG; D-GalN/LPS, $\mathrm{n}=10$ ) and treatment group (TG; T $\alpha 1 / \mathrm{D}-\mathrm{GalN} / \mathrm{LPS}, \mathrm{n}=10$ ). Survival rates were recorded for $24 \mathrm{~h}$, then all surviving rats were sacrificed. The second group $(n=63)$ was randomly subdivided into $C G(n=3)$, MG (n=30) and TG $(n=30)$. Three rats from the MG and TG groups were sacrificed at 3, 6, 9 and $12 \mathrm{~h}$ after D-GalN injection, and 3 rats from the CG were sacrificed at $3 \mathrm{~h}$ following saline injection. Rats in the CG group received an intraperitoneal injection of $2 \mathrm{ml}$ saline. Rats in the $\mathrm{MG}$ group received intraperitoneal injection of D-GalN (700 mg/kg) and LPS $(10 \mu \mathrm{g} / \mathrm{kg})$ to induce ALF. Rats in the TG group received an intraperitoneal injection of T $\alpha 1(0.03 \mathrm{mg} / \mathrm{kg}) 1 \mathrm{~h}$ before and 30 min after the establishment of the ALF model. All animal experiments were approved by the Ethics Committee of Xi'an Jiaotong University (Xi'an, China) in accordance with the guidelines of the China Laboratory Animal Management Committee.

Sample collection. Blood samples $(\sim 2 \mathrm{ml})$ were obtained by cardiac puncture in rats under $10 \%$ chloral hydrate anesthesia $(300 \mathrm{mg} / \mathrm{kg}$, intraperitoneally), and then centrifuged at $1,200 \mathrm{x} \mathrm{g}$ for $10 \mathrm{~min}$ at $25^{\circ} \mathrm{C}$. The supernatant was tested for the biochemical indices TNF- $\alpha$ and IL-10. The rats were sacrificed by cervical dislocation immediately after blood collection, and a portion of liver tissue was fixed in $6 \%$ paraformaldehyde at $4^{\circ} \mathrm{C}$ for $24 \mathrm{~h}$ in PBS for pathological examinations. Another portion of liver tissue was frozen in liquid nitrogen for subsequent measurement of Bax and Bcl-2 expression.

Liver function tests. Plasma alanine aminotransferase (ALT), aspartate aminotransferase (AST) and total bilirubin (TBIL) levels were determined using an LST008 Biochemistry Analyzer (Hitachi, Ltd., Tokyo, Japan).

Histopathology. Liver tissue, fixed in $6 \%$ paraformaldehyde in PBS, was dehydrated using ethyl alcohol. Ethyl alcohol in the tissues was then eliminated with xylene, and the liver sections embedded in paraffin for sectioning. The $5-\mu \mathrm{m}$-thick sections were stained with hematoxylin for $20 \mathrm{~min}$ and eosin for $3 \mathrm{~min}$ at $25^{\circ} \mathrm{C}$ and a light microscope was used to examine the sections.

TUNEL assay. Fixed liver tissues were permeabilized with $1 \%$ Triton X-100 for $10 \mathrm{~min}$. TUNEL staining was conducted with an In-Situ Apoptosis Detection kit, according to the manufacturer's instructions and the results were examined under a light microscope. The percentage of TUNEL-positive liver cells was calculated manually following observation. Five higher magnification images were selected to obtain a quantitative analysis of the positive cells, and the apoptotic index (AI) was calculated as follows: AI $(\%)=$ apoptotic cell number/total cell number x 100.

ELISA assay. Plasma levels of TNF- $\alpha$ and IL-10 were measured with ELISA kits, according to the manufacturer's instructions. 
Reverse transcription-quantitative polymerase chain reaction (RT-qPCR). RT-qPCR for the analysis of Bax and Bcl-2 was performed as previously described (18). Briefly, total RNA was extracted from liver tissue using RNA Extraction kits. mRNA was converted to cDNA using a Sensiscript RT kit according to the manufacturer's instructions and qPCR was performed using SYBR-Green Master mix, according to the manufacturer's instructions. The sequences of the primers used are presented in Table I. $\beta$-actin was used as an internal control and the $2^{-\Delta \Delta \mathrm{Cq}}$ method was used to quantify the results (19).

Western blot analysis. Liver tissue was homogenized in lysis buffer (cat. no. 78510) with protease inhibitor (cat. no. 78443) (both from Thermo Fisher Scientific, Inc.) by sonication. Protein concentration was determined using Pierce ${ }^{\mathrm{TM}}$ BCA assay (cat. no. 23225; Thermo Fisher Scientific, Inc.) Total lysate $(50 \mu \mathrm{g} /$ lane) was separated by $12 \%$ SDS-PAGE and transferred to polyvinylidene fluoride membranes. The membranes were then blocked with $5 \%$ milk for $1 \mathrm{~h}$ at $25^{\circ} \mathrm{C}$ and incubated with primary antibodies against Bcl-2 (dilution 1:500), Bax (dilution 1:500) and GAPDH (dilution $1: 1,000)$. for $24 \mathrm{~h}$ at $4^{\circ} \mathrm{C}$. After washing, the membranes were incubated with appropriate HRP-conjugated secondary antibodies (dilution 1:5,000) at room temperature for $2 \mathrm{~h}$. Protein bands obtained were visualized using an enhanced chemiluminescence system (cat. no. 35055; Thermo Fisher Scientific, Inc.). The protein bands were detected using the Bio-Rad ChemiDoc ${ }^{\mathrm{TM}}$ MP imaging system (Bio-Rad Laboratories, Inc., Hercules, CA, USA).

Statistical analysis. Statistical analyses were performed using SPSS version 16.0 (SPSS, Inc., Chicago, IL, USA) and GraphPad Prism 5 (GraphPad Software, Inc., La Jolla, CA, USA). Survival was evaluated using life tables constructed from survival data with Kaplan-Meier plots. The comparisons with the model group were assessed using analysis of variance followed by post hoc multiple comparison tests (Tukey's) at each time-point. $\mathrm{P}<0.05$ was considered to indicate a statistically significant difference.

\section{Results}

Tal treatment improves survival in ALF. As shown in Fig. 1, all rats in the CG survived for $24 \mathrm{~h}$, whereas the number of animals that died increased over time (from 3 to $24 \mathrm{~h}$ ) in the MG and TG. The survival rate of the rats was significantly higher in the TG as compared with the MG (60 vs. $30 \%, \mathrm{P}=0.0248)$.

Tal reduces liver injury in ALF. As shown in Tables II-IV, the plasma levels of ALT, AST and TBIL were significantly higher in the TG and $\mathrm{MG}$ compared with the $\mathrm{CG}$ at all time-points $(\mathrm{P}<0.05)$. Furthermore, the levels in the TG were significantly lower compared with the MG at all time-points $(\mathrm{P}<0.05)$, with the exception of TBIL at $3 \mathrm{~h}$.

Typical hepatic histopathological features are presented in Fig. 2. Liver samples from the control rats exhibited an intact hepatic structure with normal hepatic lobule, and an absence of hepatocellular necrosis, hemorrhage or inflammatory cell infiltration (Fig. 2C). By contrast, notable damage was observed in the MG (Fig. 2A) and TG (Fig. 2B) samples. Evident destruction
Table I. Primer sequences for polymerase chain reaction.

\begin{tabular}{ll}
\hline Genes & \multicolumn{1}{c}{ Primer } \\
\hline 3-actin & F:5'-TCTGTGTGGATTGGTGGCTCTA-3' \\
& R:5'-CTGCTTGCTGATCCACATCTG-3' \\
Bcl-2 & F:5'-GGGATGCCTTTGTGGAACTATATG-3' \\
& R:5'-TGAGCAGCGTCTTCAGAGACA-3' \\
Bax & F:5'-GACACCTGAGCTGACCTTGGA-3' \\
& R:5'-GACACTCGCTCAGCTTCTTGGT-3' \\
\hline
\end{tabular}

Bcl-2, B-cell lymphoma 2; Bax, Bcl-2-associated X protein.

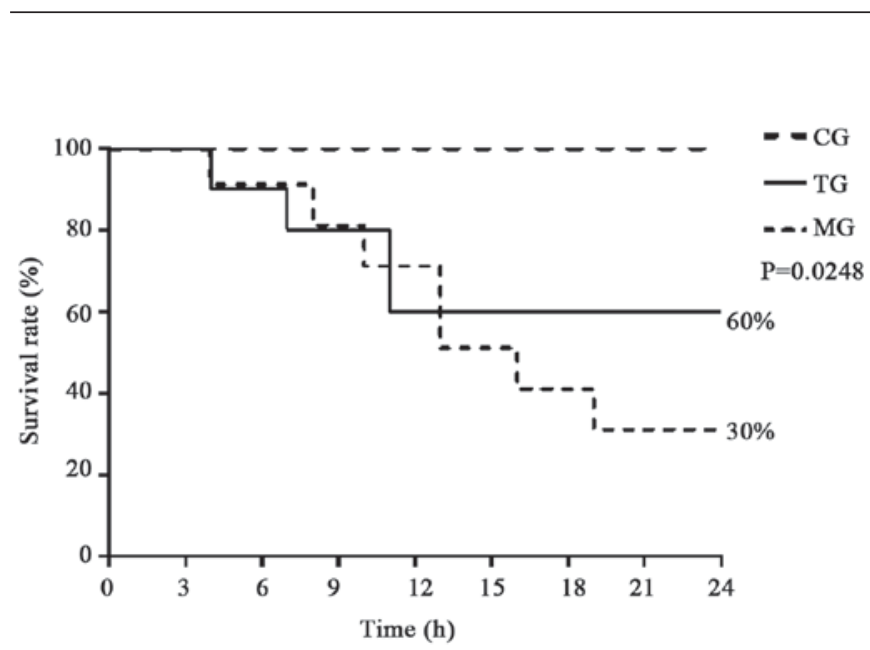

Figure 1. T $\alpha$ treatment improves the survival rate in a rat model of acute liver failure. Rats receiving a T $\alpha 1$ injection demonstrated a higher survival rate compared with the MG at $24 \mathrm{~h}(60$ vs. $30 \%, \mathrm{P}=0.0248)$. T $\alpha 1$, thymosin $\alpha 1$; $\mathrm{CG}$, control group; $\mathrm{MG}$, model group; TG, treatment group.

of architecture was observed, with a large number of apoptotic and necrotic cells in the two groups. In addition, infiltrating cells and congested red blood cells in the sinusoids were observed. Furthermore, the features of ALF were aggravated over time (3-12 h) in the MG and TG. Notably, in the Ta1-treated rats, the hepatocytes appeared healthier, with fewer apoptotic cells, as compared with those from the MG at the same time-points.

Tal inhibits pro-inflammatory TNF- $\alpha$ and promotes anti-inflammatory IL-10. Plasma TNF- $\alpha$ (Fig. 3A) and IL-10 (Fig. 3B) levels were significantly higher in the MG and TG compared with the $\mathrm{CG}$ at $3 \mathrm{~h}(\mathrm{P}<0.05)$. Furthermore, the levels of TNF- $\alpha$ and IL-10 increased in the MG and TG at each time-point from 3 to $12 \mathrm{~h}$. The level of TNF- $\alpha$ was significantly lower in the TG compared with the $\mathrm{MG}$ at each time-point ( $3 \mathrm{~h}, \mathrm{P}<0.001 ; 6 \mathrm{~h}, \mathrm{P}<0.001 ; 9 \mathrm{~h}, \mathrm{P}=0.005 ; 12 \mathrm{~h}, \mathrm{P}<0.001)$, whereas IL-10 was significantly higher in the TG compared with the MG ( $3 \mathrm{~h}, \mathrm{P}=0.008 ; 6 \mathrm{~h}, \mathrm{P}=0.003 ; 9 \mathrm{~h}, \mathrm{P}=0.002 ; 12 \mathrm{~h}$, $\mathrm{P}=0.009$ ).

Tal inhibits hepatocyte apoptosis in ALF. As shown in Fig. 4, apoptotic liver cells were observed in the MG (Fig. 4A) and TG (Fig. 4B). The liver cell AI was significantly higher in the MG and TG compared with the CG at each time-point. The liver cell $\mathrm{AI}$ in the MG and TG increased at each time-point from 3 to $12 \mathrm{~h}$ (Fig. 4C). The AI in the TG was significantly lower 
Table II. Measurements of ALT values at each time-point.

\begin{tabular}{lcccc}
\hline & \multicolumn{3}{c}{ ALT $(\mathrm{U} / \mathrm{l})$} \\
\cline { 2 - 5 } Group & $3 \mathrm{~h}$ & $6 \mathrm{~h}$ & $9 \mathrm{~h}$ & $12 \mathrm{~h}$ \\
\hline CG & $33.33 \pm 4.84$ & & & \\
MG & $1,379.33 \pm 4.33^{\mathrm{a}}$ & $2,894.50 \pm 5.21^{\mathrm{a}}$ & $4,991.97 \pm 553.30^{\mathrm{a}}$ & $9,297.43 \pm 81.54^{\mathrm{a}}$ \\
TG & $985.50 \pm 3.80^{\mathrm{a}, \mathrm{b}}$ & $1,863.34 \pm 36.89^{\mathrm{a}, \mathrm{b}}$ & $2,583.35 \pm 174.73^{\mathrm{a}, \mathrm{b}}$ & $6,187.67 \pm 182.89^{\mathrm{a}, \mathrm{b}}$ \\
\hline
\end{tabular}

Data are presented as the mean \pm standard deviation. ${ }^{\mathrm{a}} \mathrm{P}<0.05$ vs. $\mathrm{CG} ;{ }^{\mathrm{b}} \mathrm{P}<0.05$ vs. MG. ALT, alanine aminotransferase; $\mathrm{CG}$, control group; MG, model group; TG, treatment group.

Table III. Measurements of AST values at each time-point.

\begin{tabular}{lcccc}
\hline & \multicolumn{3}{c}{ AST (U/l) } & \\
\cline { 2 - 5 } Group & $3 \mathrm{~h}$ & $6 \mathrm{~h}$ & $9 \mathrm{~h}$ & $12 \mathrm{~h}$ \\
\hline CG & $34.67 \pm 1.53$ & & & \\
MG & $847.40 \pm 43.34^{\mathrm{a}}$ & $1,321.36 \pm 29.26^{\mathrm{a}}$ & $3,442.00 \pm 409.67^{\mathrm{a}}$ & $6,778.00 \pm 91.60^{\mathrm{a}}$ \\
TG & $622.33 \pm 58.77^{\mathrm{a}, \mathrm{b}}$ & $999.71 \pm 99.03^{\mathrm{a}, \mathrm{b}}$ & $2,159.00 \pm 179.41^{\mathrm{a}, \mathrm{b}}$ & $4,415.00 \pm 171.56^{\mathrm{a}, \mathrm{b}}$ \\
\hline
\end{tabular}

Data are presented as the mean \pm standard deviation. ${ }^{a} \mathrm{P}<0.05$ vs. $\mathrm{CG} ;{ }^{\mathrm{b}} \mathrm{P}<0.05$ vs. MG. AST, aspartate aminotransferase; $\mathrm{CG}$, control group; MG, model group; TG, treatment group.

Table IV. Measurements of TBIL values at each time-point.

$\operatorname{TBIL}(\mu \mathrm{mol} / \mathrm{l})$

\begin{tabular}{lcccc}
\cline { 2 - 4 } Group & $3 \mathrm{~h}$ & $6 \mathrm{~h}$ & $9 \mathrm{~h}$ & $12 \mathrm{~h}$ \\
\hline CG & $3.76 \pm 0.45$ & & & \\
MG & $7.07 \pm 0.61^{\mathrm{a}}$ & $11.60 \pm 1.08^{\mathrm{a}}$ & $16.30 \pm 0.87^{\mathrm{a}}$ & $22.50 \pm 2.11^{\mathrm{a}}$ \\
TG & $6.97 \pm 0.60^{\mathrm{a}}$ & $9.23 \pm 0.49^{\mathrm{a}, \mathrm{b}}$ & $11.37 \pm 0.50^{\mathrm{a}, \mathrm{b}}$ & $14.67 \pm 0.45^{\mathrm{a}, \mathrm{b}}$
\end{tabular}

Data are presented as the mean \pm standard deviation. ${ }^{\mathrm{a}} \mathrm{P}<0.05$ vs. CG; ${ }^{\mathrm{b}} \mathrm{P}<0.05$ vs. MG. TBIL, total bilirubin; CG, control group; MG, model group; TG, treatment group.

compared with that in the MG at 6,9 and $12 \mathrm{~h}(6 \mathrm{~h}, \mathrm{P}<0.001 ; 9 \mathrm{~h}$, $\mathrm{P}=0.002 ; 12 \mathrm{~h}, \mathrm{P}<0.001)$.

To confirm the apoptotic changes in the liver, Bax and Bcl-2 were investigated in ALF with or without T $\alpha 1$ treatment, using RT-qPCR (Fig. 5A and B) and western blot analysis (Fig. 5C and D). Bax mRNA expression was significantly increased in the TG and MG compared with the CG at $3 \mathrm{~h}$ (Fig. 5A). The expression of Bax mRNA (Fig. 5A) and Bax protein (Fig. 5C) increased over time, from 3 to $12 \mathrm{~h}$. The mRNA expression of Bax was significantly higher in the MG compared with the TG at each time-point $(3 \mathrm{~h}, \mathrm{P}=0.02 ; 6 \mathrm{~h}$, $\mathrm{P}=0.016 ; 9 \mathrm{~h}, \mathrm{P}=0.039 ; 12 \mathrm{~h}, \mathrm{P}=0.016)$. However, compared with the $\mathrm{CG}, \mathrm{Bcl}-2$ mRNA expression was significantly decreased in the TG and MG at all time-points (Fig. 5B). Bcl-2 mRNA (Fig. 5B) and protein (Fig. 5D) expression decreased over time, from 3 to $12 \mathrm{~h}$. Bcl-2 mRNA expression was significantly lower in the $\mathrm{MG}$ compared with the $\mathrm{TG}$ at each time-point $(3 \mathrm{~h}$, $\mathrm{P}=0.005 ; 6$ h, $\mathrm{P}<0.001 ; 9$ h, $\mathrm{P}=0.018 ; 12$ h, $\mathrm{P}=0.01$ ).

\section{Discussion}

The present study aimed to investigate the effects of T $\alpha 1$ in a rat model of ALF, and to establish an experimental basis for the administration of T $\alpha 1$ in the treatment of ALF. The results demonstrated that administration of T $\alpha 1$, following the development of ALF, decreased plasma levels of ALT, AST, TBIL and TNF- $\alpha$. T $\alpha 1$ administration resulted in significantly higher plasma IL-10, together with reduced hepatic histological damage. T $\alpha 1$ administration also improved the survival rates in this ALF rat model, suggesting that T $\alpha$ exerted an overall beneficial effect by reducing the inflammatory reaction, decreasing cell damage and enhancing immune function in ALF rats. 
A
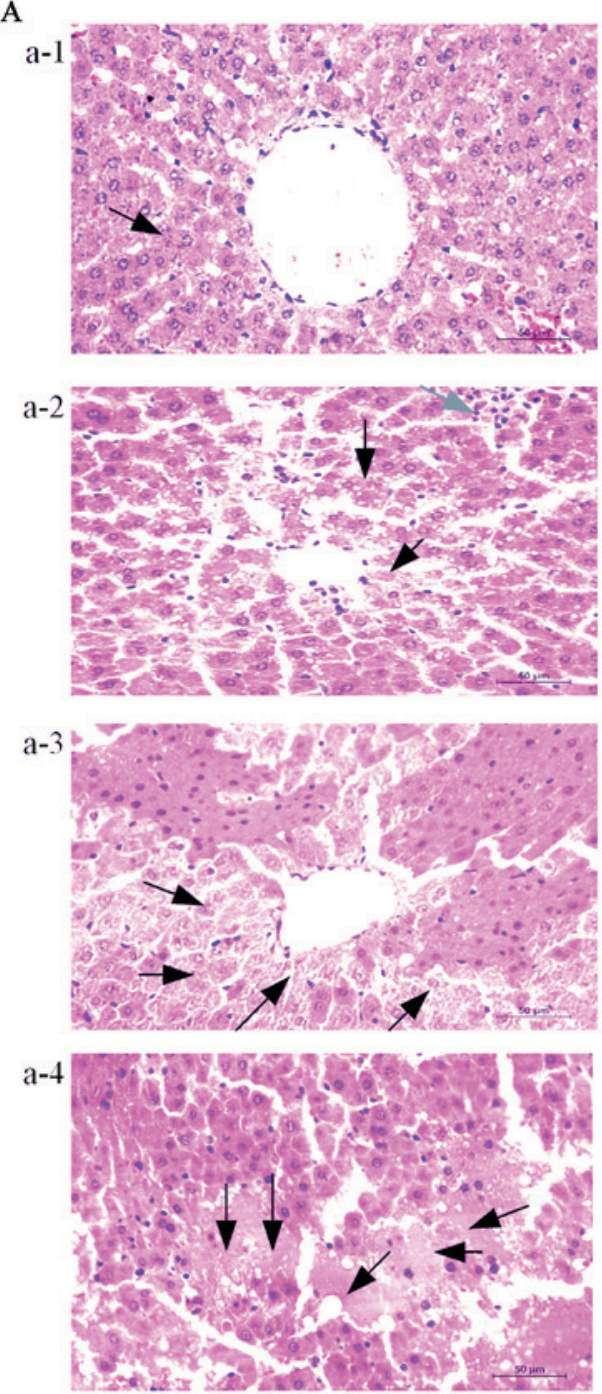

B

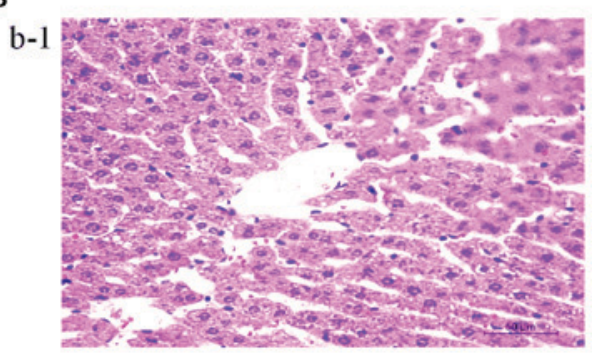

b-2

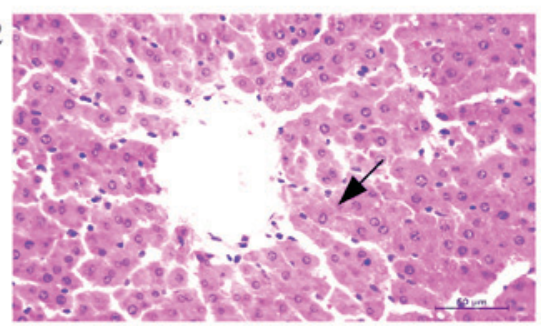

b-3
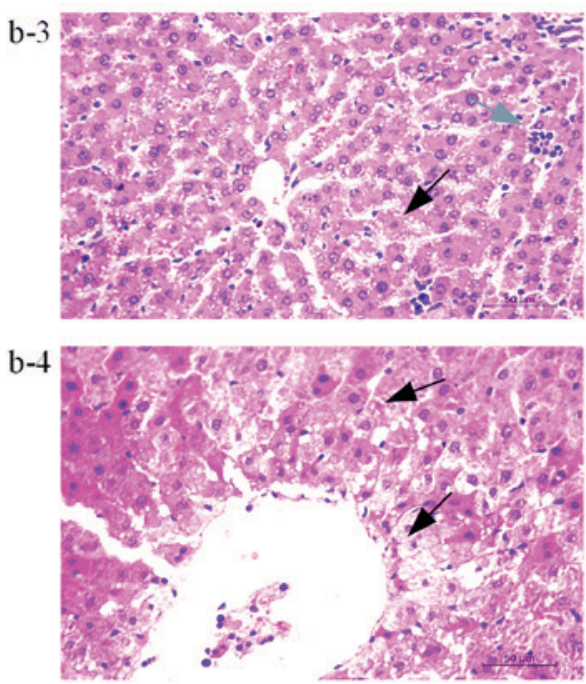

$\mathrm{C}$

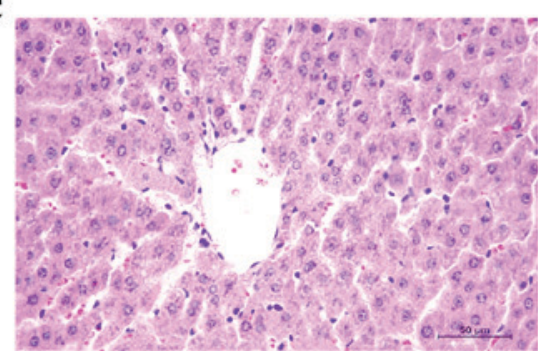

Figure 2. Thymosin $\alpha 1$ treatment attenuates hepatic tissue injury in D-galactosamine hydrochloride/lipopolysaccharide-induced ALF. Liver tissues were harvested at 3,6,9 and $12 \mathrm{~h}$ after the establishment of ALF for histopathological examination (magnification, $\mathrm{x} 400$ ). Representative images from 3 rats/ group were selected. (A) MG at A-1, 3 h; A-2, 6 h; A-3, 9 h; and A-4, 12 h. (B) TG at B-1, 3 h; B-2, 6 h; B-3, 9 h; and B-4, 12 h. (C) CG 3 h. Black arrows indicate apoptosis and necrosis, grey arrows indicate inflammatory cell infiltration. ALF, acute liver failure; CG, control group; MG, model group; TG, treatment group.

T $\alpha 1$ has been clinically demonstrated to exert an immune modulatory activity by promoting the maturation of $\mathrm{T}$ cells and natural killer cells, activating dendritic cells (20-22), increasing cytokine production, and modulating major histocompatibility complex class I surface molecules and tumor antigens $(23,24)$. Therefore, T $\alpha 1$ has been used to treat hepatitis B, resistance to infection and breast cancer $(13,25,26)$. T $\alpha 1$ is a peptide that affects multiple immune subsets associated with immune suppression (27). Furthermore, previous studies have reported that Ta1 serves a critical function in balancing pro- and anti-inflammatory cytokine production through the involvement of distinct TLRs acting on different dendritic cell subsets and the MyD88-dependent signaling pathway (28). T $\alpha 1$ may attenuate tissue injury and reduce the mortality rate through reducing the release of inflammatory factors and cytokines, and increasing IL-10 to control inflammation $(21,29,30)$.

Increased necrosis and apoptosis of hepatocytes is believed to release various inflammatory cytokines in ALF (31). 
A

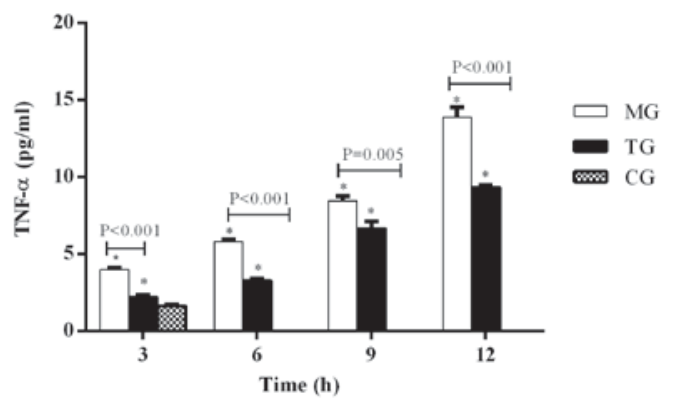

B

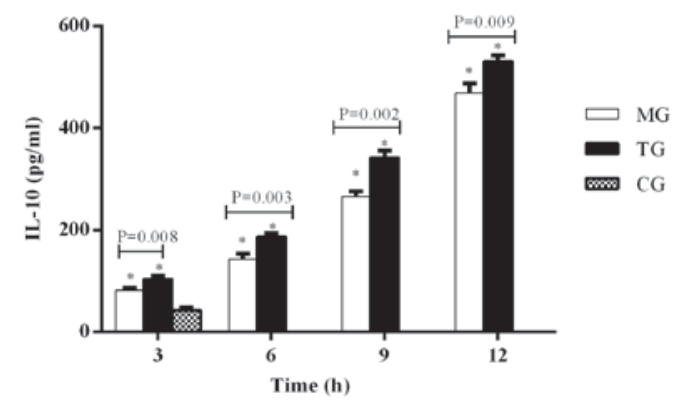

Figure 3. Thymosin $\alpha 1$ treatment inhibits pro-inflammatory TNF- $\alpha$ and promotes anti-inflammatory IL-10. Plasma (A) TNF- $\alpha$ and (B) IL-6 levels. Data are expressed as the mean \pm standard error of the mean $(n=3)$. $P<0.05$ vs. the CG group. TNF- $\alpha$, tumor necrosis factor- $\alpha$; IL-10, interleukin-10; CG, control group; MG, model group; TG, treatment group.

A

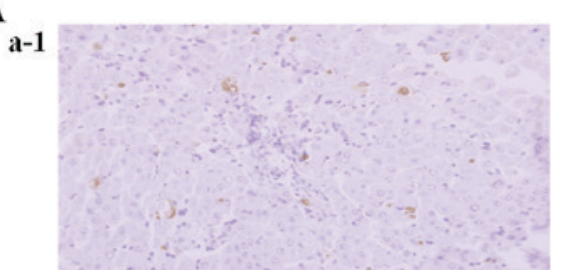

a-2

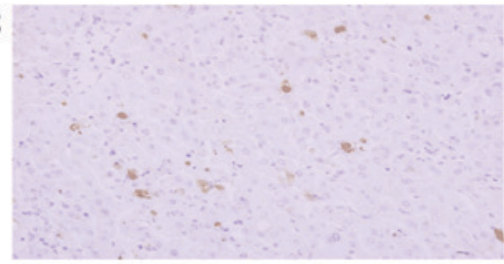

a-3

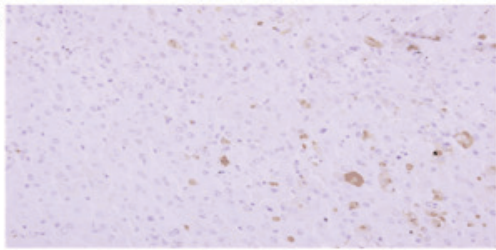

a-4

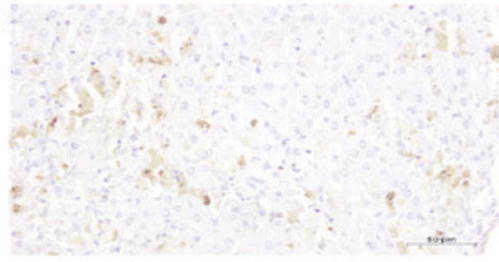

C

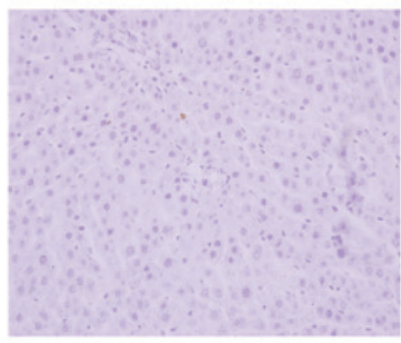

D
B

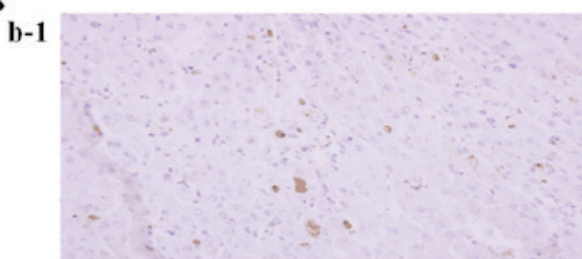

b-2

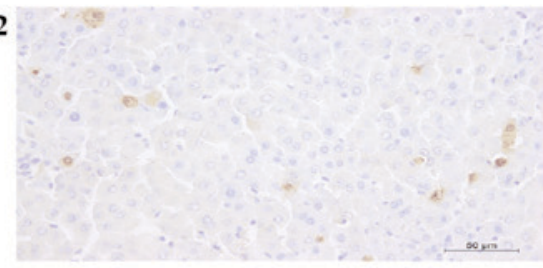

b-3

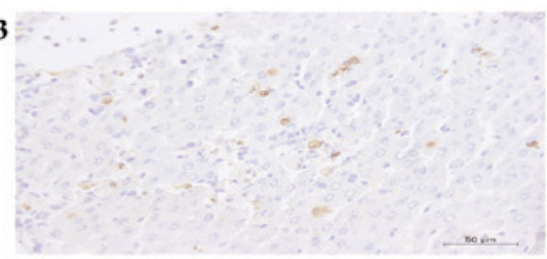

b-4
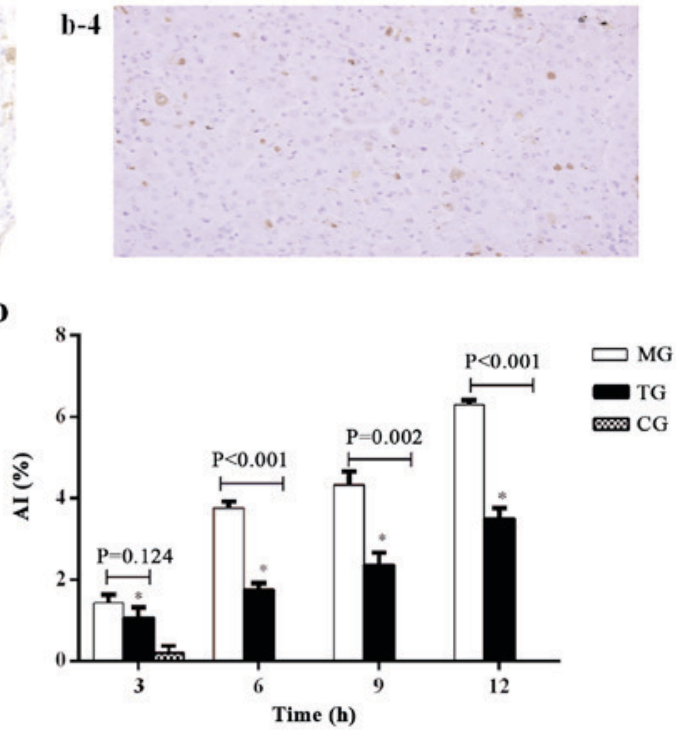

Figure 4. Thymosin $\alpha 1$ treatment inhibits hepatocyte apoptosis in D-galactosamine hydrochloride/lipopolysaccharide-induced ALF. Liver tissues were harvested at 3,6,9 and $12 \mathrm{~h}$ after the establishment of a rat model of ALF and a TUNEL assay was performed (magnification, $\mathrm{x} 400$ ). Representative images from 3 rats/group were selected. (A) MG at a-1, 3 h; a-2, 6 h; a-3, 9 h; and a-4, 12 h. (B) TG at b-1, 3 h; b-2, 6 h; b-3, 9 h; and b-4, 12 h. (C) CG 3 h. (D) Quantification of liver cell apoptosis. Data are expressed as the mean \pm standard error of the mean $(\mathrm{n}=3)$. " $\mathrm{P}<0.05$ vs. the CG group. ALF, acute liver failure; CG, control group; MG, model group; TG, treatment group; AI, apoptotic index. 
A

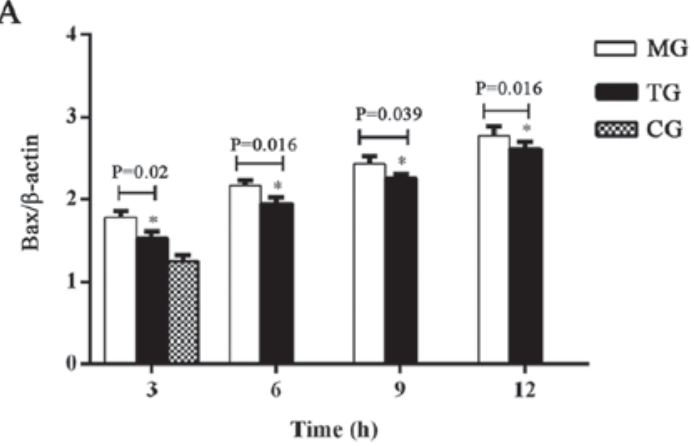

B

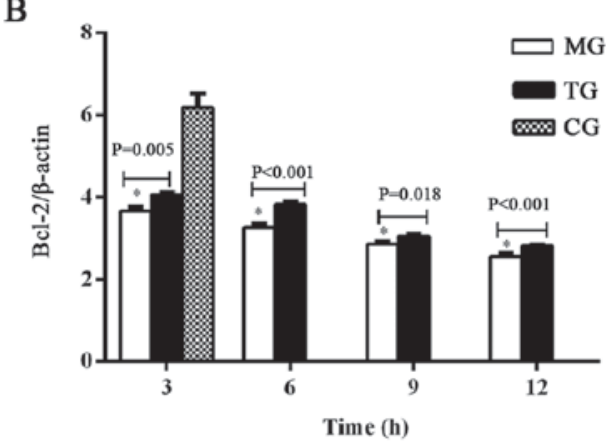

C
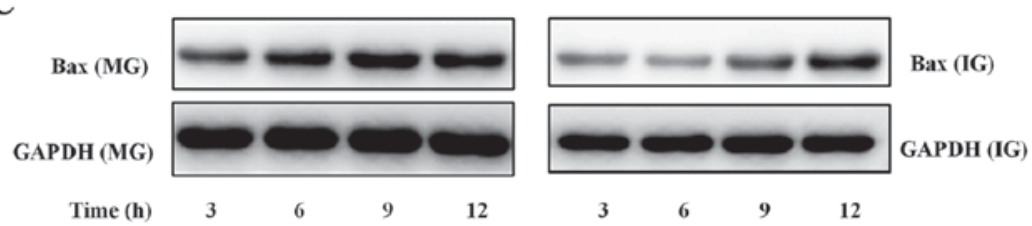

D
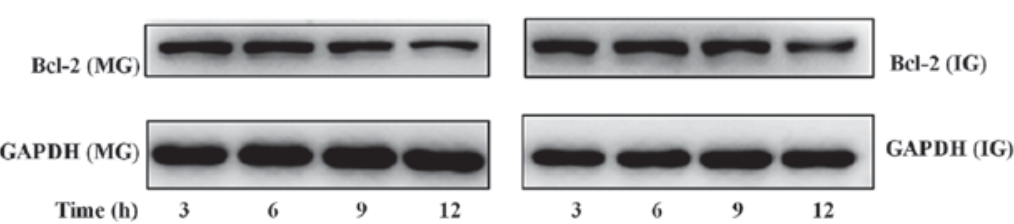

Figure 5. Effect of thymosin $\alpha 1$ treatment on the expression of Bax and Bcl-2 in liver tissue. (A) mRNA levels of Bax. (B) mRNA levels of Bcl-2. (C) Bax protein expression. (D) Bcl-2 protein expression. Data are expressed as the mean \pm standard error of the mean ( $\mathrm{n}=3$ ). ${ }^{*} \mathrm{P}<0.05$ vs. the $\mathrm{CG}$ group. $\mathrm{CG}$, control group; MG, model group; TG, treatment group; AI, apoptotic index; Bcl-2, B-cell lymphoma 2; Bax, Bcl-2-associated X protein.

TNF- $\alpha$ serves a key function in liver injury and hepatic apoptosis $(32,33)$. Pro-inflammatory TNF- $\alpha$ expression is markedly upregulated in ALF, which is critical to reducing the survival rate of mouse models of ALF induced by D-GalN/LPS (34). The present study identified that TNF- $\alpha$ and $\mathrm{AI}$ in the TG were lower compared with those in the MG following T $\alpha 1$ treatment, suggesting that $\alpha \alpha 1$ reduced TNF- $\alpha$ levels through the inhibition of apoptosis to counteract liver failure. Furthermore, the rat mortality rate decreased with $\mathrm{T} \alpha 1$ treatment, in line with the changes in TNF- $\alpha$.

IL-10 is a key cytokine derived from T cells, macrophages and monocytes, which is able to inhibit the production of multiple immune active cytokines and to alleviate tissue damage $(35,36)$. A shift to IL-10 production occurs following the pro-inflammatory phase and this shift is initiated by high TNF- $\alpha$ levels (37). In a previous study, although serum concentrations of TNF- $\alpha$ and IL-10 were increased in ALF, treatment with IL-10 resulted in normalization of aminotransferase levels, improved liver histology and reduced fibrosis (38). In addition, administration of recombinant IL-10 prior to the establishment of ALF has been demonstrated to reduce the production of these pro-inflammatory cytokines and improve liver injury (39). The present study identified that the plasma levels of IL-10 were higher in the TG compared with the MG after T $\alpha 1$ treatment, indicating that $\mathrm{T} \alpha 1$ promoted the anti-inflammatory cytokine IL-10 to suppress excessive immune response (particularly inflammatory TNF- $\alpha$ ) and prevent further liver cell apoptosis. Ta1 can also affect the relative ability of dendritic cells to balance $\mathrm{T}$ helper cells and regulatory $\mathrm{T}$ cells to stimulate IL-10 in vitro and in vivo (28). IL-10 in turn negatively regulates the immune response and prevents a large excess of cytokines, known as a 'cytokine storm' (40).

However, the present study should be regarded as a pilot study, as it only investigated plasma TNF- $\alpha$ and IL-10, and the results of immunomodulation in animal models do not directly translate to clinical settings. Further investigations are required at the biochemical level (including additional liver function and cytokine testing) and molecular level (such as gene expression studies) in order to fully understand the immunological mechanisms underlying ALF and the effects of T $\alpha 1$.

In conclusion, the use of immunomodulatory agent $\mathrm{T} \alpha 1$ may have beneficial effects in ALF by alleviating inflammatory responses and reducing cell, tissue and organ damage. Therefore, the clinical application of immunomodulation therapy in ALF treatment deserves further investigation.

\section{Acknowledgements}

The present study was supported by The National Science and Technology Major Project (grant no. 2012ZX10002004-007).

\section{References}

1. Karkhanis J, Verna EC, Chang MS, Stravitz RT, Schilsky M, Lee WM and Brown RS Jr; Acute Liver Failure Study Group: Steroid use in acute liver failure. Hepatology 59: 612-621, 2014.

2. Sarin SK and Choudhury A: Acute-on-chronic liver failure: Terminology, mechanisms and management. Nat Rev Gastroenterol Hepatol 13: 131-149, 2016. 
3. Wu Z, Han M, Chen T, Yan W and Ning Q: Acute liver failure: Mechanisms of immune-mediated liver injury. Liver Int 30: 782-794, 2010.

4. European Association for The Study of the Liver. Electronic address: easloffice@easloffice.eu; Clinical practice guidelines panel, Wendon, J; Panel members, Cordoba J, Dhawan A, Larsen FS, Manns M, Samuel D, et al: EASL clinical practical guidelines on the management of acute (fulminant) liver failure. J Hepatol 66 : 1047-1081, 2017.

5. Xu X, Liu X, Ling Q, Wei Q, Liu Z, Xu X, Zhou L, Zhang M, Wu J, Huang J, et al: Artificial liver support system combined with liver transplantation in the treatment of patients with acute-on-chronic liver failure. PLoS One 8: e58738, 2013.

6. Krenkel O, Mossanen JC and Tacke F: Immune mechanisms in acetaminophen-induced acute liver failure. Hepatobiliary Surg Nutr 3: 331-343, 2014.

7. Jalan R, Gines P, Olson JC, Mookerjee RP, Moreau R, Garcia-Tsao G, Arroyo V and Kamath PS: Acute-on chronic liver failure. J Hepatol 57: 1336-1348, 2012.

8. Donnelly MC, Hayes PC and Simpson KJ: Role of inflammation and infection in the pathogenesis of human acute liver failure: Clinical implications for monitoring and therapy. World J Gastroenterol 22: 5958-5970, 2016.

9. Antoniades CG, Berry PA, Wendon JA and Vergani D: The importance of immune dysfunction in determining outcome in acute liver failure. J Hepatol 49: 845-861, 2008.

10. Possamai LA, Thursz MR, Wendon JA and Antoniades CG: Modulation of monocyte/macrophage function: A therapeutic strategy in the treatment of acute liver failure. J Hepatol 61 439-445, 2014.

11. Chadwick D, Pido-Lopez J, Pires A, Imami N, Gotch F, Villacian JS, Ravindran S and Paton NI: A pilot study of the safety and efficacy of thymosin alpha 1 in augmenting immune reconstitution in HIV-infected patients with low CD4 counts taking highly active antiretroviral therapy. Clin Exp Immunol 134: 477-481, 2003.

12. Qiu SJ, Zhou ZG, Shen F, Li AJ, Chen MS, Ying MG, Chen Z, Zhang YX, Sun HC and Fan J: A multicenter, randomized, observation-controlled clinical trial to evaluate the efficacy and safety of thymalfasin adjuvant therapy in patients with HBV-related HCC after curative resection-first announcement of the protocol. Expert Opin Biol Ther 15 (Suppl 1): S133-S137, 2015.

13. Lao X, Li B, Liu M, Shen C, Yu T, Gao X and Zheng H: A modified thymosin alpha 1 inhibits the growth of breast cancer both in vitro and in vivo: Suppressment of cell proliferation, inducible cell apoptosis and enhancement of targeted anticancer effects. Apoptosis 20: 1307-1320, 2015.

14. Romani L,Bistoni F, Montagnoli C, Gaziano R, Bozza S, Bonifazi P, Zelante T, Moretti S, Rasi G, Garaci E and Puccetti P: Thymosin alpha1: An endogenous regulator of inflammation, immunity, and tolerance. Ann N Y Acad Sci 1112: 326-338, 2007.

15. Liu F, Wang HM, Wang T, Zhang YM and Zhu X: The efficacy of thymosin alphal as immunomodulatory treatment for sepsis: A systematic review of randomized controlled trials. BMC Infect Dis 16: 488, 2016.

16. Wu J, Zhou L, Liu J, Ma G, Kou Q, He Z, Chen J, Ou-Yang B, Chen M, Li Y, et al: The efficacy of thymosin alpha 1 for severe sepsis (ETASS): A multicenter, single-blind, randomized and controlled trial. Crit Care 17: R8, 2013.

17. Li C, Bo L, Liu Q and Jin F: Thymosin alphal based immunomodulatory therapy for sepsis: A systematic review and meta-analysis. Int J Infect Dis 33: 90-96, 2015.

18. Xu Y, Wang H, Bao S, Tabassam F, Cai W, Xiang X, Zhao G, Wu H, Gao T, Li H and Xie Q: Amelioration of liver injury by continuously targeted intervention against TNFRp55 in rats with acute-on-chronic liver failure. PLoS One 8: e68757, 2013.

19. Livak KJ and Schmittgen TD: Analysis of relative gene expression data using real-time quantitative PCR and the 2(-Delta Delta C(T)) method. Methods 25: 402-408, 2001.

20. Peng Y, Chen Z, Yu W, Zhou Q, Xu L, Mao FF, Huang G, Zhang X, Li S, Lahn BT and Xiang AP: Effects of thymic polypeptides on the thymopoiesis of mouse embryonic stem cells. Cell Biol Int 32: 1265-1271, 2008.

21. Romani L, Bistoni F, Gaziano R, Bozza S, Montagnoli C, Perruccio K, Pitzurra L, Bellocchio S, Velardi A, Rasi G, et al Thymosin alpha 1 activates dendritic cells for antifungal Th1 resistance through toll-like receptor signaling. Blood 103 4232-4239, 2004.

22. Yao PL, Lin YC, Sawhney P and Richburg JH: Transcriptional regulation of FasL expression and participation of sTNF-alpha in response to sertoli cell injury. J Biol Chem 282: 5420-5431, 2007.
23. Xu YG, Guan XT, Liu ZM, Tian CY and Cui LC: Immunogenicity in swine of orally administered recombinant Lactobacillus plantarum expressing classical swine fever virus E2 protein in conjunction with thymosin $\alpha-1$ as an adjuvant. Appl Environ Microbiol 81: 3745-3752, 2015.

24. Garaci E, Pica F, Serafino A, Balestrieri E, Matteucci C, Moroni G, Sorrentino R, Zonfrillo M, Pierimarchi P and Sinibaldi-Vallebona P: Thymosin $\alpha 1$ and cancer: Action on immune effector and tumor target cells. Ann N Y Acad Sci 1269: 26-33, 2012.

25. Naylor PH and Mutchnick MG: Immunotherapy for hepatitis B in the direct acting antiviral era: Reevaluating the thymosin $\alpha 1$ efficacy trials in the light of a combination therapy approach. J Viral Hepat: Oct 20,2017 (Epub ahead of print).

26. Camerini $\mathrm{R}$ and Garaci E: Historical review of thymosin $\alpha$ 1 in infectious diseases. Expert Opin Biol Ther 15 (Suppl 1): S117-S127, 2015.

27. King R and Tuthill C: Immune modulation with thymosin alpha 1 treatment. Vitam Horm 102: 151-178, 2016.

28. Romani L, Bistoni F, Perruccio K, Montagnoli C, Gaziano R, Bozza S, Bonifazi P, Bistoni G, Rasi G, Velardi A, et al: Thymosin alpha1 activates dendritic cell tryptophan catabolism and establishes a regulatory environment for balance of inflammation and tolerance. Blood 108: 2265-2274, 2006.

29. Bozza S, Gaziano R, Bonifazi P, Zelante T, Pitzurra L, Montagnoli C, Moretti S, Castronari R, Sinibaldi P, Rasi G, et al: Thymosin alphal activates the TLR9/MyD88/ IRF7-dependent murine cytomegalovirus sensing for induction of anti-viral responses in vivo. Int Immunol 19: 1261-1270, 2007.

30. Yang X, Qian F, He HY, Liu KJ, Lan YZ, Ni B, Tian Y, Fu XL, Zhang J, Shen ZG, et al: Effect of thymosin alpha-1 on subpopulations of Th1, Th2, Th17, and regulatory T cells (Tregs) in vitro. Braz J Med Biol Res 45: 25-32, 2012.

31. Nakama T, Hirono S, Moriuchi A, Hasuike S, Nagata K, Hori T, Ido A, Hayashi K and Tsubouchi H: Etoposide prevents apoptosis in mouse liver with D-galactosamine/lipopolysaccharide-induced fulminant hepatic failure resulting in reduction of lethality. Hepatology 33: 1441-1450, 2001.

32. Chastre A, Belanger M, Beauchesne E, Nguyen BN, Desjardins P and Butterworth RF: Inflammatory cascades driven by tumor necrosis factor-alpha play a major role in the progression of acute liver failure and its neurological complications. PLoS One 7: e49670, 2012.

33. Wang K: Molecular mechanisms of hepatic apoptosis. Cell Death Dis 5: e996, 2014.

34. Zhang P, Shen H, Huang J, Wang H, Zhang B, Zhou R, Zhong B and Fan X: Intraperitoneal administration of fetuin-A attenuates D-galactosamine/lipopolysaccharide-induced liver failure in mouse. Dig Dis Sci 59: 1789-1797, 2014.

35. Boomer JS, To K, Chang KC, Takasu O, Osborne DF, Walton AH, Bricker TL, Jarman SD II, Kreisel D, Krupnick AS, et al: Immunosuppression in patients who die of sepsis and multiple organ failure. JAMA 306: 2594-2605, 2011.

36. Chen X, Wang Y, Luo H, Luo Z, Liu L, Xu W, Zhang T, Yang N, Long X, Zhu N, et al: Ulinastatin reduces urinary sepsisrelated inflammation by upregulating IL10 and downregulating TNF- $\alpha$ levels. Mol Med Rep 8: 29-34, 2013.

37. Volk HD, Reinke P and Döcke WD: Clinical aspects: From systemic inflammation to 'immunoparalysis'. Chem Immunol 74: 162-177, 2000.

38. Nagaki M, Iwai H, Naiki T, Ohnishi H, Muto Y and Moriwaki H: High levels of serum interleukin-10 and tumor necrosis factor-alpha are associated with fatality in fulminant hepatitis. J Infect Dis 182: 1103-1108, 2000.

39. Leifeld L, Cheng S, Ramakers J, Dumoulin FL, Trautwein C, Sauerbruch $\mathrm{T}$ and Spengler U: Imbalanced intrahepatic expression of interleukin 12, interferon gamma, and interleukin 10 in fulminant hepatitis B. Hepatology 36: 1001-1008, 2002.

40. Orabona C, Puccetti P, Vacca C, Bicciato S, Luchini A, Fallarino F, Bianchi R, Velardi E, Perruccio K, Velardi A, et al: Toward the identification of a tolerogenic signature in IDO-competent dendritic cells. Blood 107: 2846-2854, 2006.

This work is licensed under a Creative Commons Attribution-NonCommercial-NoDerivatives 4.0 International (CC BY-NC-ND 4.0) License. 